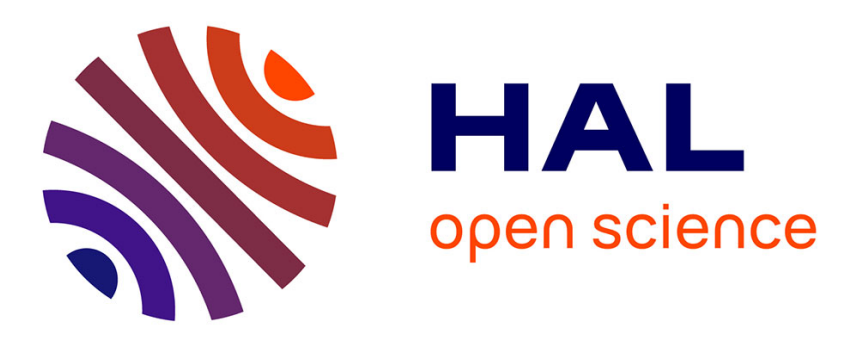

\title{
Identification of the fragmentation of brittle particles during compaction process by the acoustic emission technique
}

Nathalie Favretto-Cristini, Lise Hégron, Philippe Sornay

\section{To cite this version:}

Nathalie Favretto-Cristini, Lise Hégron, Philippe Sornay. Identification of the fragmentation of brittle particles during compaction process by the acoustic emission technique. Ultrasonics, 2016, 67, pp.178189. 10.1016/j.ultras.2015.12.010 . hal-01308080

\section{HAL Id: hal-01308080 \\ https://hal.science/hal-01308080}

Submitted on 26 Oct 2021

HAL is a multi-disciplinary open access archive for the deposit and dissemination of scientific research documents, whether they are published or not. The documents may come from teaching and research institutions in France or abroad, or from public or private research centers.
L'archive ouverte pluridisciplinaire HAL, est destinée au dépôt et à la diffusion de documents scientifiques de niveau recherche, publiés ou non, émanant des établissements d'enseignement et de recherche français ou étrangers, des laboratoires publics ou privés.

\section{(c)(1)}

Distributed under a Creative Commons Attribution| 4.0 International License 


\title{
Identification of the fragmentation of brittle particles during compaction process by the acoustic emission technique
}

\author{
Nathalie Favretto-Cristini ${ }^{\mathrm{a}, *}$, Lise Hégron ${ }^{\mathrm{a}, \mathrm{b}, 1}$, Philippe Sornay ${ }^{\mathrm{b}}$ \\ a LMA, CNRS UPR7051, Aix-Marseille Univ., Centrale Marseille, F-13453 Marseille Cedex 13, France \\ ${ }^{\mathrm{b}}$ CEA, DEN, DEC, SFER, LCU, F-13108 Saint Paul Lez Durance, France
}

\begin{abstract}
Some nuclear fuels are currently manufactured by a powder metallurgy process that consists of three main steps, namely preparation of the powders, powder compaction, and sintering of the compact. An optimum between size, shape and cohesion of the particles of the nuclear fuels must be sought in order to obtain a compact with a sufficient mechanical strength, and to facilitate the release of helium and fission gases during irradiation through pores connected to the outside of the pellet after sintering. Being simple to adapt to nuclear-oriented purposes, the Acoustic Emission (AE) technique is used to control the microstructure of the compact by monitoring the compaction of brittle Uranium Dioxide $\left(\mathrm{UO}_{2}\right)$ particles of a few hundred micrometers. The objective is to identify in situ the mechanisms that occur during the $\mathrm{UO}_{2}$ compaction, and more specifically the particle fragmentation that is linked to the open porosity of the nuclear matter. Three zones of acoustic activity, strongly related to the applied stress, can be clearly defined from analysis of the continuous signals recorded during the compaction process. They correspond to particle rearrangement and/or fragmentation. The end of the noteworthy fragmentation process is clearly defined as the end of the significant process that increases the compactness of the material. Despite the fact that the wave propagation strongly evolves during the compaction process, the acoustic signature of the fragmentation of a single $\mathrm{UO}_{2}$ particle and a bed of $\mathrm{UO}_{2}$ particles under compaction is well identified. The waveform, with a short rise time and an exponential-like decay of the signal envelope, is the most reliable descriptor. The impact of the particle size and cohesion on the AE activity, and then on the fragmentation domain, is analyzed through the discrete AE signals. The maximum amplitude of the burst signals, as well as the mean stress corresponding to the end of the recorded AE, increase with increasing mean diameter of the particles. Moreover, the maximum burst amplitude increases with increasing particle cohesion.
\end{abstract}

\section{Introduction}

The nuclear fuels of light water power reactors are currently manufactured by a powder metallurgy process that consists of three main steps: preparation of the powders, powder compaction, and sintering of the compact. This process will also be used for the production of fuels containing long-lived minor actinides (such as americium) to transform them into short-lived or stable nuclides in a fast reactor. Given their radiotoxicity, these fuels need to be manufactured in hot cells. Therefore, it is necessary to simplify the

\footnotetext{
* Corresponding author at: LMA, CNRS UPR7051, 4 impasse Nikola Tesla, CS 40006, F-13453 Marseille Cedex 13, France. Tel.: +33 484524270.

E-mail address: favretto@lma.cnrs-mrs.fr (N. Favretto-Cristini).

1 Present address: Centre Technologique Méditerranéen de Métrologie, F-13250 StChamas, France.
}

manufacturing process as much as possible, thereby limiting the dissemination and retention of the nuclear matter.

In addition, in order to facilitate the release of helium and fission gases during irradiation, a majority of the pores of the fuels must be connected to the outside of the pellet after sintering. However, this open porosity must also permit mechanical handling in the industrial manufacturing process. An optimum between size, shape and cohesion of the particles of the nuclear fuels must be sought in order to obtain a compact with a sufficient mechanical strength [1-3], while respecting the specifications of the sintered product.

Using brittle particles of several hundred micrometers seems to be a good solution to obtain both compacts with open porosity and limitation of the dissemination of the nuclear matter. These particles may be obtained by Calcined Resin Microsphere Pelletization process [4]. Our work is concerned with brittle Uranium Dioxide 
$\left(\mathrm{UO}_{2}\right)$ particles, obtained by mechanical granulation of $\mathrm{UO}_{2}$ powder, whose size ranges between 160 and $500 \mu \mathrm{m}$. These particles will be called "granules" hereafter.

The aim of our work is also to propose a technique that controls the process that should be easy to implement and robust in a hostile and hardly reachable environment. As the density of the medium monotonically increases with the applied stress (Fig. 1), it is impossible to highlight a change in compaction mechanism that could inform on the amount of porosity. Therefore, we propose to control the microstructure of the compact by monitoring the compaction of the brittle particles using the Acoustic Emission (AE) technique. This technique has the advantage of being simple to adapt to nuclear-oriented purposes.

The AE technique is a powerful tool dedicated to structure health monitoring (the term "structure" having to be understood here in an overall meaning). This technique has found so many applications in civil engineering [5-7], industrial pharmacy [8], geophysics $[9,10]$, and materials science [11-16], that it is impossible here to review all the books and articles related to this topic. The $\mathrm{AE}$ technique is generally used to monitor real-time processes that emit acoustic waves. It is also used to detect and/or monitor defaults and cracks in materials [17-19], and to monitor the compaction of metallic $[20,21]$, pharmaceutical $[22,23]$ or ceramic [24] powders. Indeed, the final step of the process (i.e. the ejection of the compact) may create defaults inside the compact that can be detected through the comparison of the number of the acoustic events and AE energy rate between the undamaged compacts and the damaged counterparts. Some works also focus on the correlation between mechanisms during compaction (e.g. deformation, fragmentation, friction, etc.) and acoustic signatures [25]. Nevertheless they usually consider continuous signals and the evolution of the number of counts, rarely the discrete signals and the evolution of parameters such as amplitude, waveform, rise time, time duration, and frequency. Moreover, the $\mathrm{AE}$ technique is strongly dependent on the structure and the material of interest, and the analogies should be done with caution. To our knowledge, studies concerned with $\mathrm{UO}_{2}$ are very rare and focused essentially to the detection of defaults during the material compaction using amplitude and $V_{\text {rms }}$ analysis [24,26]. In our case, the objective is to identify in situ the mechanisms that occur during the $\mathrm{UO}_{2}$ compaction, and more specifically the particle fragmentation that is linked to the open porosity of the nuclear matter, in order to infer the evolution of the material microstructure. In our work continuous as well discrete signals are considered and relevant descriptors of the fragmentation are sought. In a previous paper [27] we put in evidence the acoustic signature of fragmentation of a single $\mathrm{UO}_{2}$ granule under compaction. Here we present some additional results and we focus more specifically on the acoustic signatures

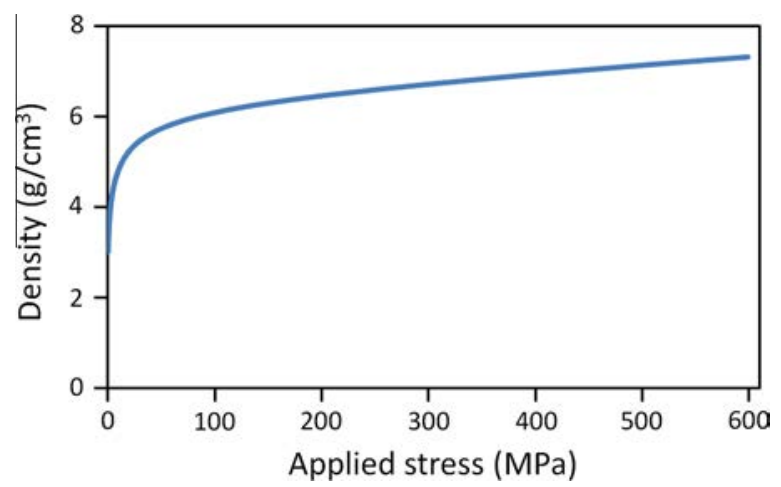

Fig. 1. Evolution of the density of the $\mathrm{UO}_{2}$ granules as a function of the stress applied during the compaction process. of the mechanisms occurring in a bed of granules. The main difficulty lies in the fact that the wave propagation strongly evolves during the compaction process, since the $\mathrm{UO}_{2}$ medium is a loose granular medium at the beginning of the process and becomes a consolidated porous medium at the end.

The paper is organized as follows. Section 2 describes the properties of the $\mathrm{UO}_{2}$ particles as well as the experimental set-up, namely the compression system coupled to the AE set-up. In Section 3 we present some new results concerning the acoustic signature of fragmentation of a single granule. Section 4 is focused on the AE during the compaction of a bed of granules. More specifically, we emphasize the impact of the granule size and cohesion on the AE activity, and then on the fragmentation domain.

\section{Material and experimental setup}

\subsection{Uranium Dioxide $\left(\mathrm{UO}_{2}\right)$ granules}

$\mathrm{UO}_{2}$ compacts were obtained first by compaction of a powder at $600 \mathrm{MPa}$, whose elementary particles are submicron. These compacts were then crushed, and size sorting was performed to keep only particles with diameter ranging between 160 and $500 \mu \mathrm{m}$. These particles are called granules.

The compact density determined by weighing and measurement was $6.49 \mathrm{~g} / \mathrm{cm}^{3}$. That corresponds to a compactness of $59 \%$. The granules also have this density. They have a polyhedral shape, as shown in Fig. 2a. Their observation at higher magnification allows visualization of the elementary particles constituting the granules (Fig. 2b). Links that bind these particles are Van der Waals attractions, electrostatic forces, and capillary forces. The dendritic shape of the elementary particles also contributes to the cohesion of the granules. Some granules were thermally consolidated at 700, 1000 and $1200{ }^{\circ} \mathrm{C}$, respectively, under argon-5\% hydrogen atmosphere. At about $800{ }^{\circ} \mathrm{C} \mathrm{UO} \mathrm{U}_{2}$ starts sintering. Some solid links are thus formed between particles, which increases the mechanical strength of the granules (Fig. 3).

\subsection{Compression system and acoustic emission line}

The granules were poured into the press die and were compacted between two punches with a diameter of $10 \mathrm{~mm}$ (Fig. 4). The upper punch could move and the lower punch was fixed. The die was mobile, which allowed ejection of the compact. The upper punch moved at a speed of $0.1 \mathrm{~mm} / \mathrm{s}$ until reaching the desired applied stress. During the ejection, a pressure approximately ten times lower than the maximum applied stress was maintained on the compact, in order to control the release of the stored elastic energy during compaction, and hence to avoid cracking or delamination of the compact. Force sensors (in blue ${ }^{2}$ in Fig. 4), located directly on the punches, recorded the force applied on the upper punch and the force transmitted to the lower punch. Both forces are generally used to calculate the ability of the granules to convert an axial force into a radial force. The mean stress $\left(\sigma_{\text {mean }}\right)$ viewed by the compact is equal to the geometric mean of the applied stress and the transmitted stress. Knowing the mass of granules added in the die, the position of the upper punch at any time, the strengths, and the small deformation of the press, we could calculate the variation in density of the compact as a function of stress.

Furthermore, the die was equipped with two piezoelectric sensors (in red in Fig. 4). They recorded the Acoustic Emission (AE) during compaction using a device developed by Mistras ${ }^{\circledR}$ Company. AE sensors (Mistras ${ }^{\circledR} \mu 30$ ) of diameter $10 \mathrm{~mm}$ were used;

\footnotetext{
${ }^{2}$ For interpretation of color in Fig. 4, the reader is referred to the web version of this article.
} 


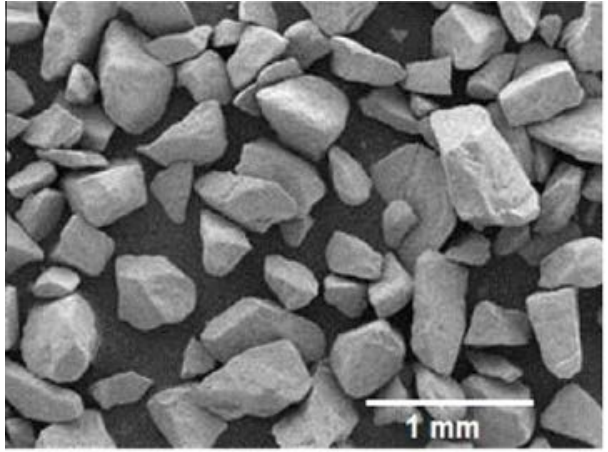

(a)

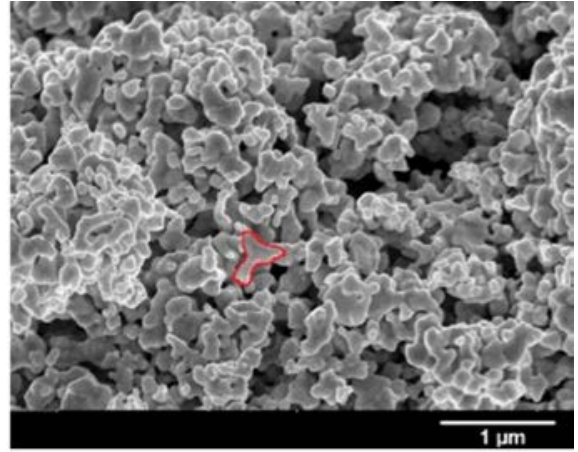

(b)

Fig. 2. SEM observations of unconsolidated $\mathrm{UO}_{2}$ granules ( $600 \mathrm{MPa}, 160-500 \mu \mathrm{m}$ ): (a) granules, and (b) elementary particles.

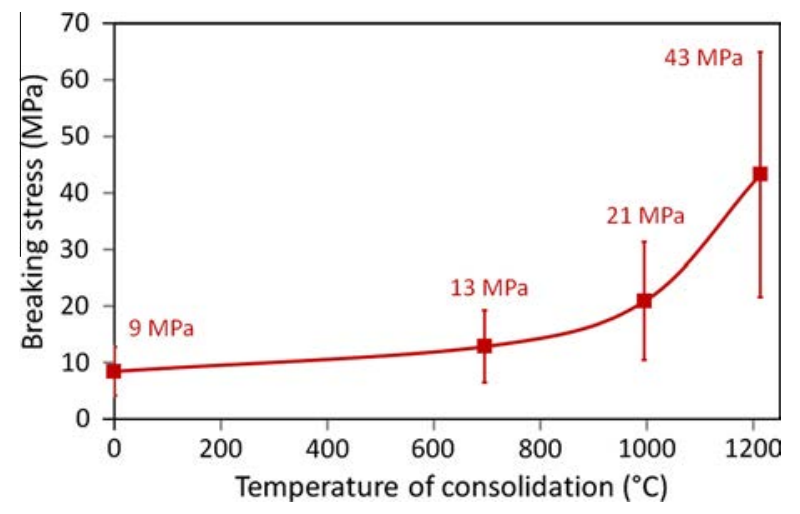

Fig. 3. Variation of the breaking stress of the $\mathrm{UO}_{2}$ granules as a function of their temperature of consolidation. The dispersion in the breaking stress at a fixed temperature results from the fact that the loading surface and the cracking surface differ from one granule to another.

they have a frequency bandwidth between $100 \mathrm{kHz}$ and $400 \mathrm{kHz}$, and two resonance frequencies at $125 \mathrm{kHz}$ and $225 \mathrm{kHz}$. To enhance the signal transmission between the die and the sensors, they were fixed to the die by means of a spring that ensures a constant holding force. Silicon grease was used as a couplant. Before each test series, we tested the quality of the sensor mounting by recording the AE produced by a pencil lead break as described in the standard "NF EN 1330-9".

Fig. 5 shows a typical burst signal of $\mathrm{AE}$ and some associated parameters. The straightforward parameter is the number of hits, i.e. the number of pulses that exceed the detection threshold. Although this parameter is strongly related to the acoustic activity, it cannot be associated to a particular phenomenon because of the diversity of emission origins in the compact (e.g., friction, fragmentation) and possible spurious noise (e.g., background noise, electromagnetic radiation, mechanical vibrations related to the machine). However, an AE caused by a given mechanism is expected to yield to a typical burst signal shape.

\section{Acoustic emission during the compaction of a single granule}

The objective of our work is to detect and to monitor in situ the fragmentation of granules in order to infer the evolution of the material microstructure. Prior to studying the AE during the compaction of a bed of granules, we found useful to examine the compaction of a single granule. We thus crushed a single granule between two punches with a diameter of $3 \mathrm{~mm}$ (Fig. 6a). The speed of the upper punch was $500 \mu \mathrm{m} / \mathrm{min}$ and the lower punch was fixed. First, the force gradually increased and then abruptly decreased. The granule then had a crack (Fig. 6b). The maximum force that is the breaking point was $1.5 \mathrm{~N} \pm 0.7 \mathrm{~N}$ (dispersion

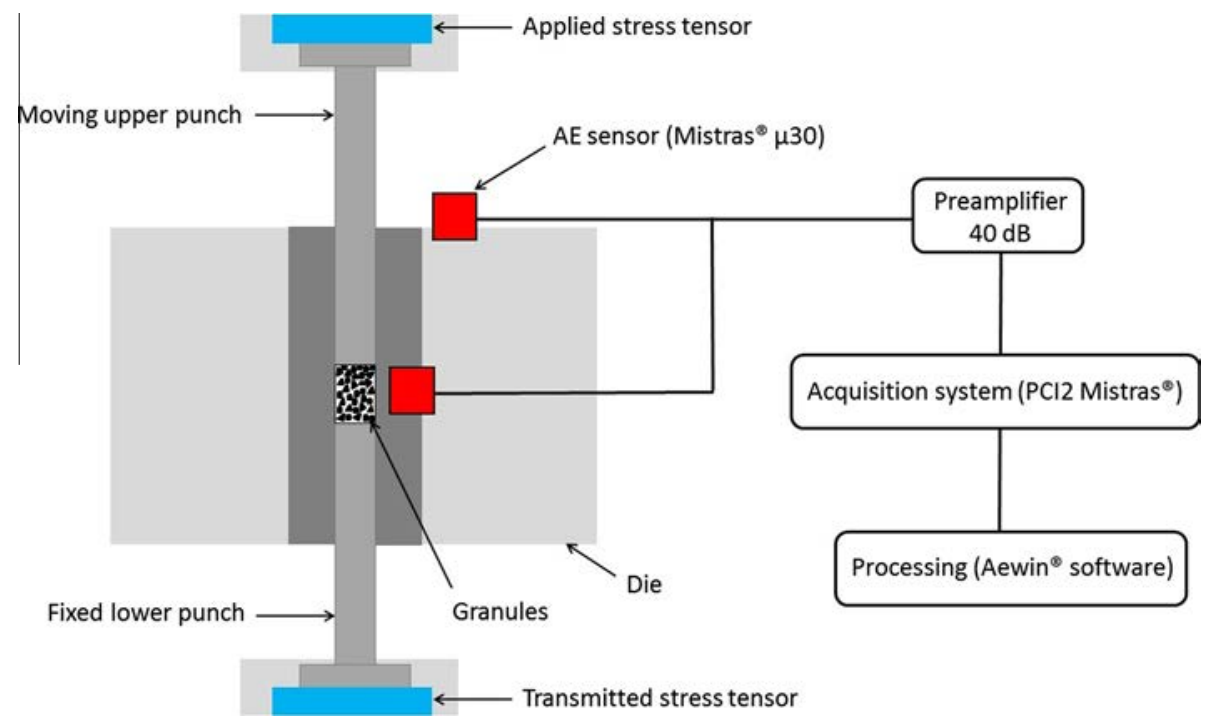

Fig. 4. Schematic representation of the compression system and the acoustic emission line with force sensors and acoustic emission sensors. 


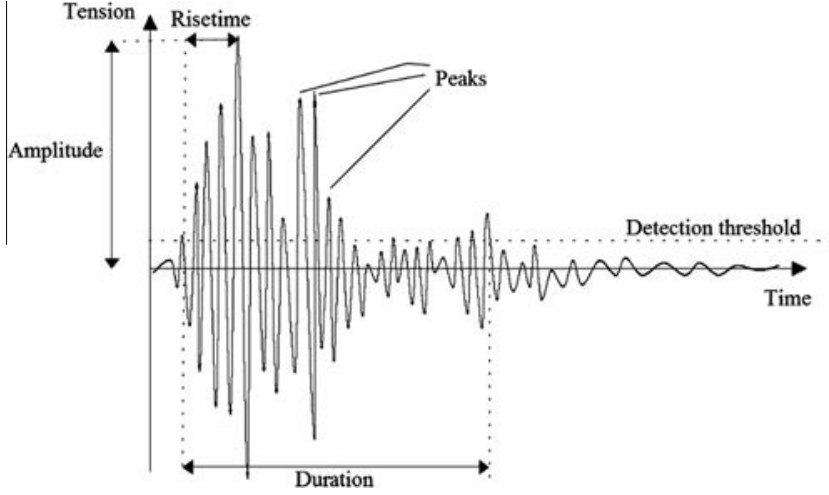

Fig. 5. Parameters of the acoustic burst signal.

obtained for a 15 granule batch). The displacement to achieve the breaking strength was approximately $80 \mu \mathrm{m}$. It corresponds to the formation of flat surfaces on the granule in contact with the punches.

At the same time we recorded $\mathrm{AE}$ with a piezoelectric sensor fixed near the lower punch (Fig. 6a). During the increase in force, no $\mathrm{AE}$ exceeded the threshold that was fixed at $25 \mathrm{~dB}$. When granule breakage occurred, a single event characterized by the acoustic burst signal shown in Fig. 7 was detected. This waveform has a shape similar to a graphite pencil lead break, i.e. a short rise time followed by an exponential-like decay of the signal envelope. This is the typical signal of the fracture, regardless of the surface on which the punch is touching. Moreover, its rise time $r$ (less than $150 \mu \mathrm{s}$, Fig. 8a) is very short compared to the duration $t$ of the whole signal (about $3 \mathrm{~ms}$ ) (Fig. 7). Time-frequency analysis of the burst signal emphasizes three predominant peak frequencies (Fig. 8b): two of them correspond to the resonance frequencies of the AE sensors (namely, 125 and $225 \mathrm{kHz}$ ), while the third one (namely, $170 \mathrm{kHz}$ ) seems to be related to the material. However, the latter frequency was not constant and varied significantly with the granule under consideration. Consequently, the frequency is not a reliable parameter to identify the fragmentation of a granule. The waveform, with a short rise time and an exponential-like decay of the signal envelope, seems to be a much more reliable candidate. The maximum amplitude of the burst signals is reported in Fig. 8. At first sight, the values ranging from 25 to $80 \mathrm{~dB}$ are dispersed for a batch of identical granules. Nevertheless the maximum signal amplitude increases with the mechanical strength of the associated granules. Indeed, the more cohesive the granules are, the higher the energy required to break them is (Fig. 8b). The results referred to as 1,9 and 16 in Fig. $8 \mathrm{~b}$ can be explained by a weak coupling between the granule and the punch. This shows how significant the experimental conditions are.

In order to emphasize the impact of the compression system on the $\mathrm{AE}$ results, we recorded $\mathrm{AE}$ signals during the diametral compression of a compact (Brazilian test), using the same AE sensor located first on the upper punch and then on the compact (Fig. 9a, position \#1 and \#2, respectively). Fig. 9b is a picture of the second test, namely the sensor directly fixed on the compact. The resulting fragmentation of a compact suffering a diametral compression is shown in Fig. 9c. Typical associated burst signals recorded by the AE sensors are represented in Fig. 10. Both signals have the same waveform. However, their other characteristics are very different (Table 1 ). The rise time and the duration of the signal recorded by the $\mathrm{AE}$ sensor on the compact are shorter than the counterparts recorded by the sensor on the upper punch. Moreover, the higher amplitude and the stronger decay of the envelope of the signal

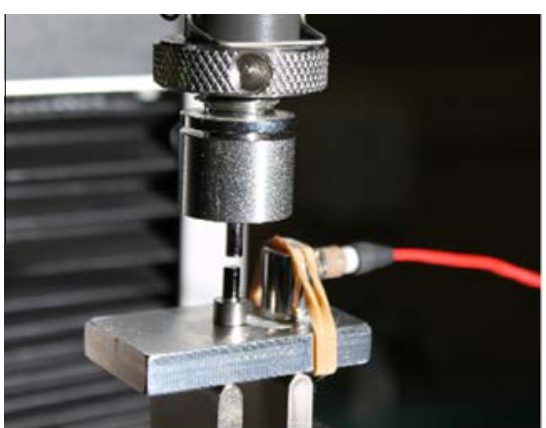

(a)

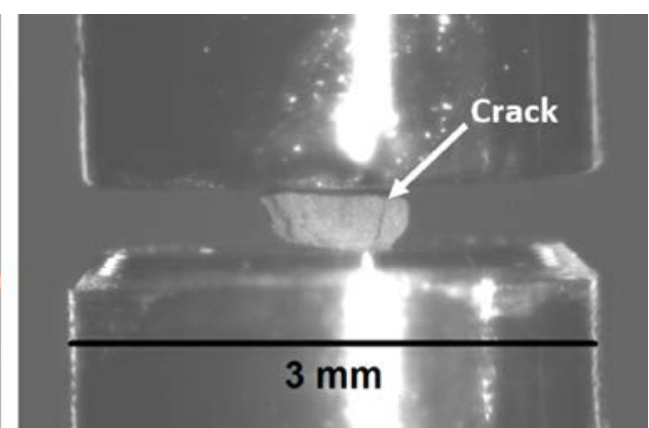

(b)

Fig. 6. (a) Micro-compression system used for crushing the $\mathrm{UO}_{2}$ granules individually, together with the acoustic emission sensor. (b) Fragmentation of a $\mathrm{UO}_{2}$ granule.

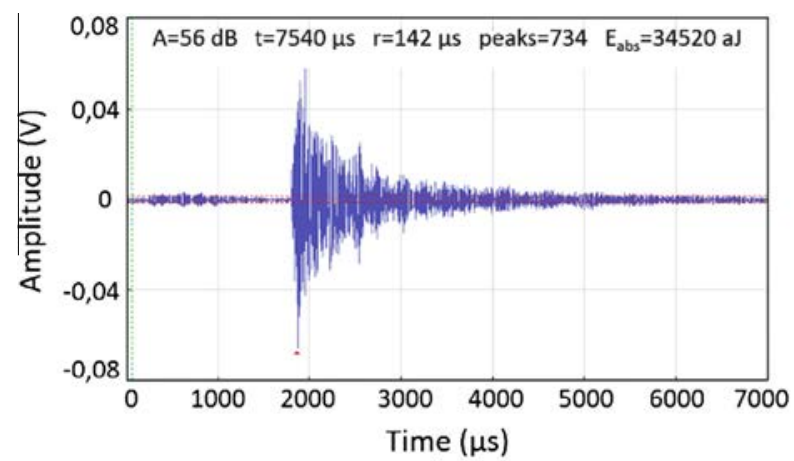

(a)

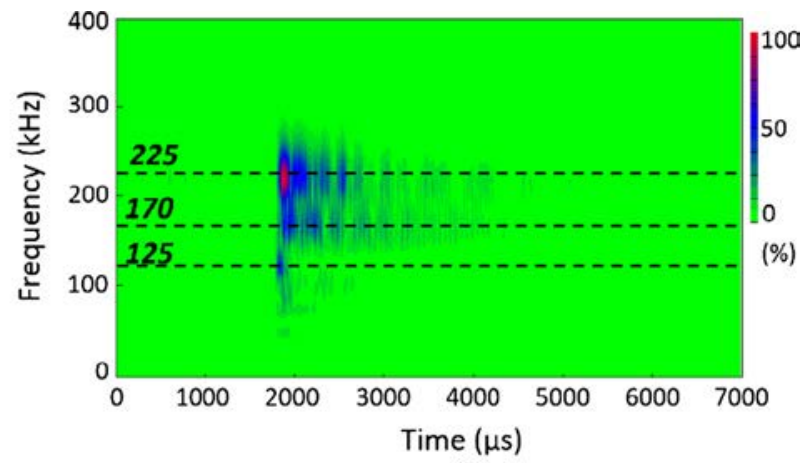

(b)

Fig. 7. (a) Acoustic burst signal emitted upon the rupture of a single $\mathrm{UO}_{2}$ granule, and (b) associated time-frequency representation. 


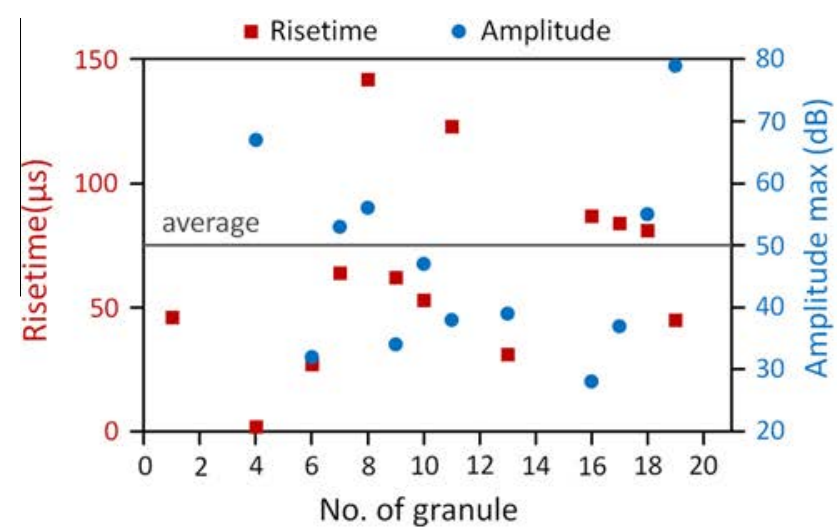

(a)

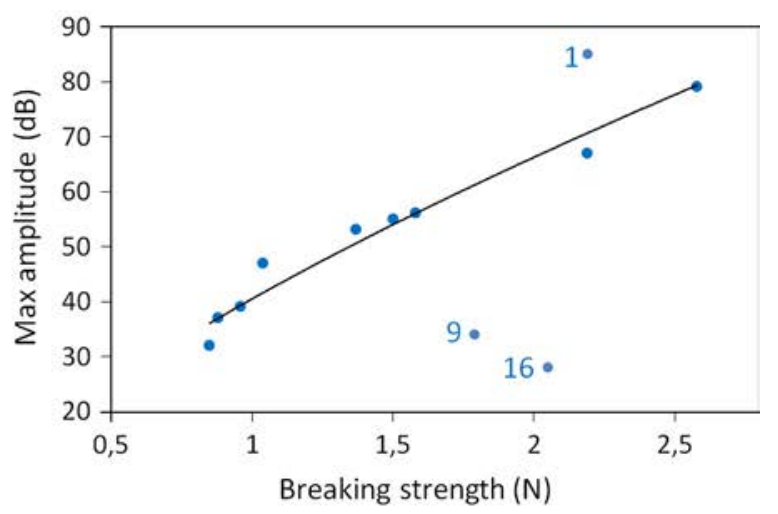

(b)

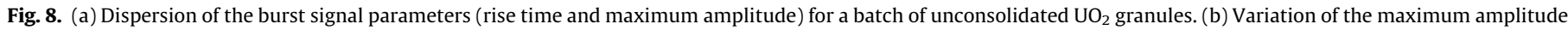
of the burst signals as a function of the breaking strength of the $\mathrm{UO}_{2}$ granules.

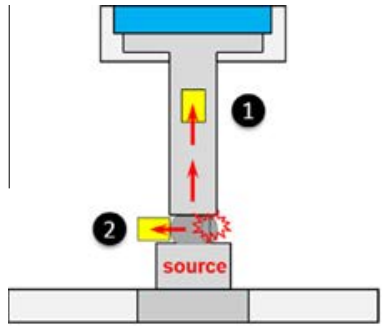

(a)

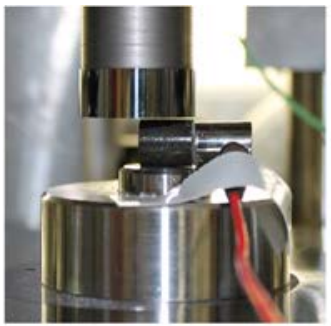

(b)

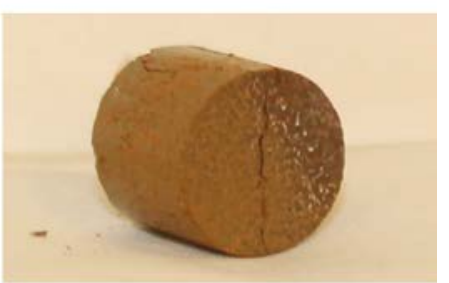

(c)

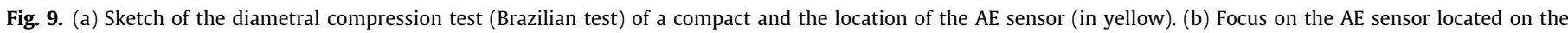

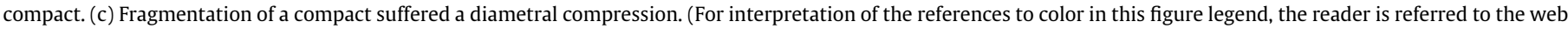
version of this article.)

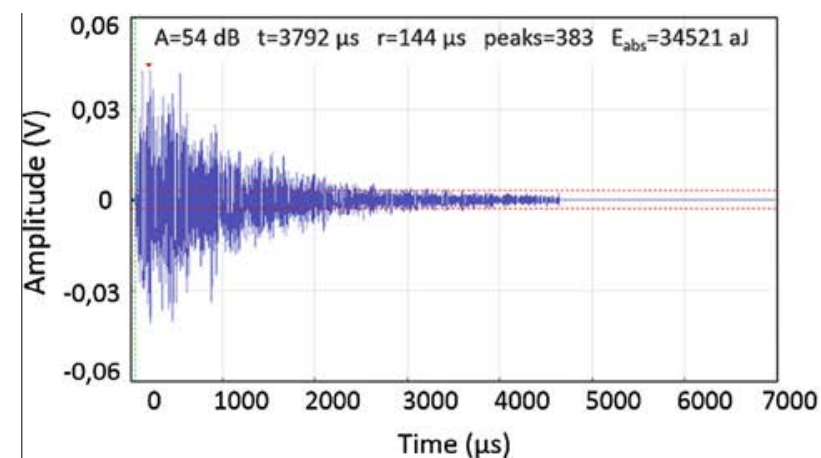

(a)

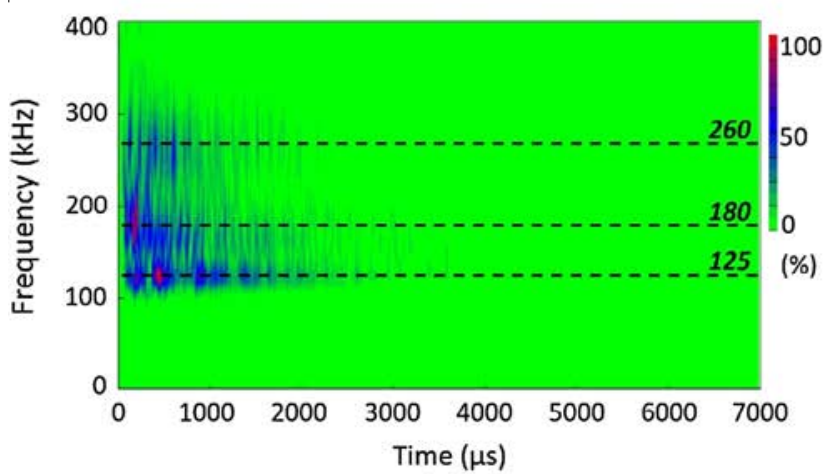

(c)

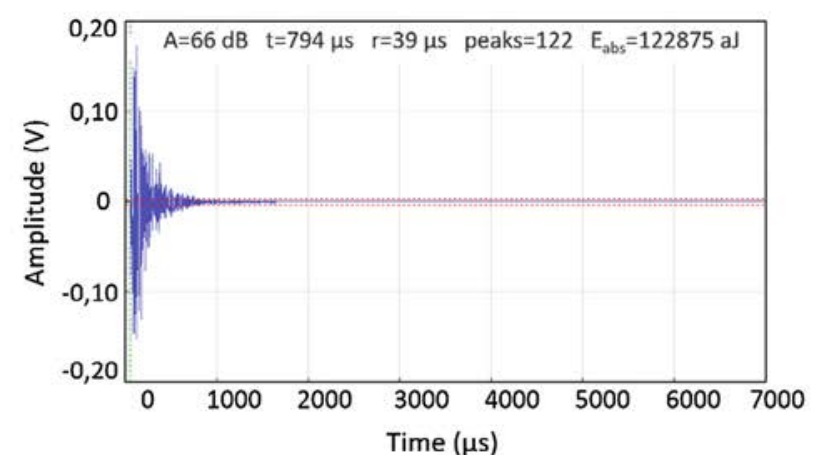

(b)

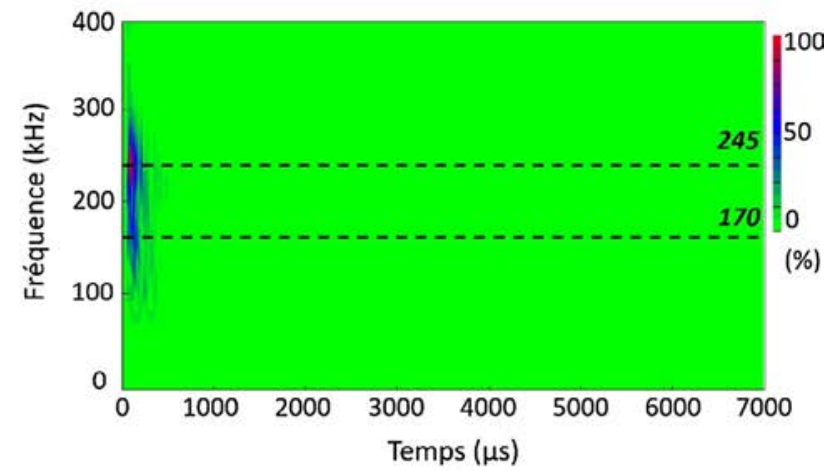

(d)

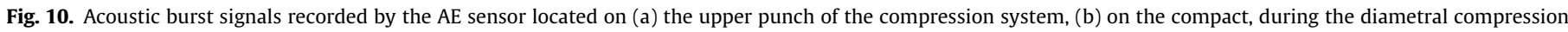
test. Associated time-frequency analysis (c and d). 
Table 1

Characteristics of the acoustic burst signals recorded by the AE sensor located on the upper punch (\#1) and on the compact (\#2), respectively (see Fig. 9a). The absolute energy is given by the integral of the square of the amplitude over the signal duration.

\begin{tabular}{llllc}
\hline & $\begin{array}{l}\text { Duration } \\
(\mu \mathrm{s})\end{array}$ & $\begin{array}{l}\text { Rise } \\
\text { time }(\mu \mathrm{s})\end{array}$ & $\begin{array}{l}\text { Max. } \\
\text { amplitude }(\mathrm{dB})\end{array}$ & $\begin{array}{l}\text { Absolute } \\
\text { energy (aJ) }\end{array}$ \\
\hline Signal of sensor \#1 & 3792 & 144 & 54 & 34,521 \\
Signal of sensor \#2 & 794 & 39 & 66 & 122,875 \\
\hline
\end{tabular}

recorded by the sensor on the compact suggest that the structure of the compression system has a significant effect on the AE results by dissipating energy and making waves dispersive. However, it does not affect the waveform that thus seems to be the most reliable parameter to identify the fragmentation during the compaction process. It should be noted that time-frequency analysis of both signals in Fig. 10 does not emphasize typical frequencies of the structure of the compression system, except the frequency $125 \mathrm{kHz}$ that also corresponds to a resonance frequency of the AE sensor.

\section{Acoustic emission during the compaction of a bed of granules}

During the compaction of a single granule, the fragmentation is the sole mechanism that can produce AE. On the contrary, during the compaction of a bed of brittle granules, several mechanisms may take place, e.g. fragmentation of granules, friction between granules, friction between granules and the die wall (however minimized by lubrication), and mechanical vibrations of the compression structure. Some of these mechanisms may generate waves with sufficiently high energy to be recorded by the AE sensor. In addition, wave propagation in a medium that evolves in a strong and continuous way is very complex. In such a context, establishing an unambiguous relationship between the mechanisms and their acoustic signatures is a difficult task. Before analyzing the $\mathrm{AE}$ signals recorded during the compaction process, we checked that most of them were generated by the granules themselves and not by the mechanical vibrations of the compression system. Indeed, the latter produces continuous signals with specific waveforms that can be well identified during an empty test consisting in a compression of the upper punch against the lower one up to $600 \mathrm{MPa}$

First, we analyze the recorded $\mathrm{AE}$ signals in a qualitative way in order to associate the signals to their potential sources. We then present a more quantitative analysis in order to emphasize the impact of the granule size and cohesion on the AE activity, and then on the fragmentation domain.

It should be noted that about five tests of compaction were performed for each batch of granules in order to study the repeatability of experiments. It was observed that the scattering of the $\mathrm{AE}$ results obtained for the tests is not significant. Consequently, although the results reported hereafter illustrate one test of compaction for each batch of granule, they are representative of all the tests.

\subsection{Qualitative analysis}

We recorded the continuous AE signal during the compaction of a bed of brittle $\mathrm{UO}_{2}$ granules. In this experiment no detection threshold of the acoustic events was applied, and the upper punch moved at the speed of $1 \mathrm{~mm} / \mathrm{s}$. This high speed, used only for this experiment, was motivated by the requirement of recording a huge amount of data during the whole compaction process. The press chamber filled up with the granules was $12 \mathrm{~mm}$ in height (filling density equal to $3.3 \mathrm{~g} / \mathrm{cm}^{3}$ ). As expected, the number of hits globally increases during the compaction process. Nevertheless, by

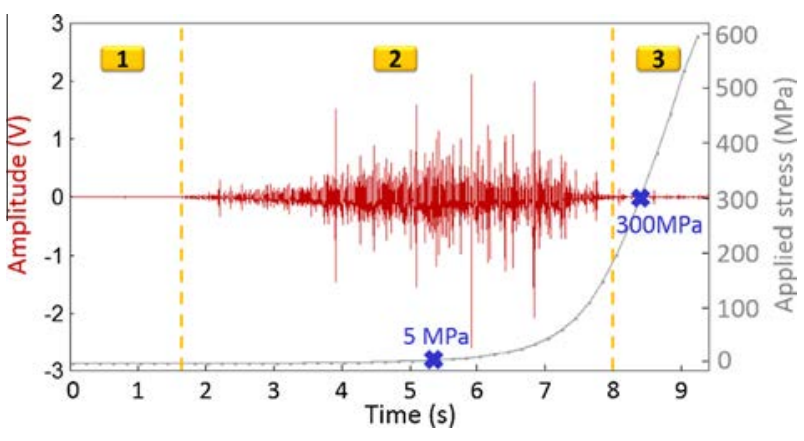

Fig. 11. Acoustic emission recorded during the compaction of a bed of brittle granules of $\mathrm{UO}_{2}$. The applied stress (grey curve) ranges from 0 to $600 \mathrm{MPa}$.

examining carefully the continuous signals, we can define three zones of acoustic activity strongly related to the applied stress (Fig. 11) [28].

The first zone, labelled 1 in Fig. 11, ranges from 0 to $1.6 \mathrm{~s}$ in the time domain. It corresponds to an applied stress ranging from 0 ( $i$. e. contact with the granules) to $0.1 \mathrm{MPa}$. The acoustic activity is globally weak and the recorded acoustic events have low energy (Fig. 12a). Indeed, the granular medium is loose at the beginning of the compaction process and waves may propagate with difficulty from their source to the sensors, or at least highly attenuated. Most of the acoustic signals have a waveform identical to that recorded for the rupture of a single granule; others have a very different waveform that remains to be associated to a specific mechanism. It might be friction between granules. At the beginning of the compaction process, the main mechanism is rearrangement of particles with sliding and friction. The compact cohesion is too weak to keep the tablet after ejection. However SEM observations show that fragmentation occurs even at very low applied stress (Fig. 12b). Fragmentation may concern the most fragile granules. Moreover, as the particles have a polyhedral shape, intergranular friction may also yield to fragmentation of granule edges. Fragmentation facilitates granule rearrangement and permits the filling of voids.

The second zone, labelled 2 in Fig. 11, ranges from 1.6 to $8 \mathrm{~s}$ in the time domain. It corresponds to an applied stress ranging from 0.1 to $180 \mathrm{MPa}$. It exhibits the most significant acoustic activity, with numerous acoustic events of high energy. The numerous acoustic events superimpose, which makes difficult signal analysis. Nevertheless, we can note that the great majority of the recorded signals is of fragmentation type (Fig. 13b). SEM observations of $\mathrm{UO}_{2}$ granules show that granules are divided in smaller parts that fill voids (Fig. 13c). In fact, a deeper analysis of the recorded acoustic signals shows that the second zone can be decomposed into three subzones. The first one, ranging from 1.6 to about $4 \mathrm{~s}$ in the time domain, exhibits many burst signals that can be easily separated in the time domain, and an increase in the amplitude of the signal envelope. However, the amplitude remains quite low, ranging between 30 and $50 \mathrm{~dB}$. Indeed, as the applied stress is low (less than $5 \mathrm{MPa}$ ), many voids between granules still exist and there are few fragmentations of granules. The second subzone, ranging from about 4 to $7 \mathrm{~s}$ in the time domain, exhibits superimposition of numerous burst signals of high amplitude (ranging from 30 to $85 \mathrm{~dB}$ ). The significant increase in the applied stress (from 5 to $50 \mathrm{MPa}$ ) implies that the medium becomes denser and denser. The granule rearrangements are performed less easily, leading to fragmentation of numerous granules. The third subzone, lying above $7 \mathrm{~s}$ in the time domain, corresponds to a strong increase in the applied stress that ranges from 50 to $180 \mathrm{MPa}$. The acoustic activity decreases together with the maximum amplitude of the signals. Indeed, the voids are rare and the granule 


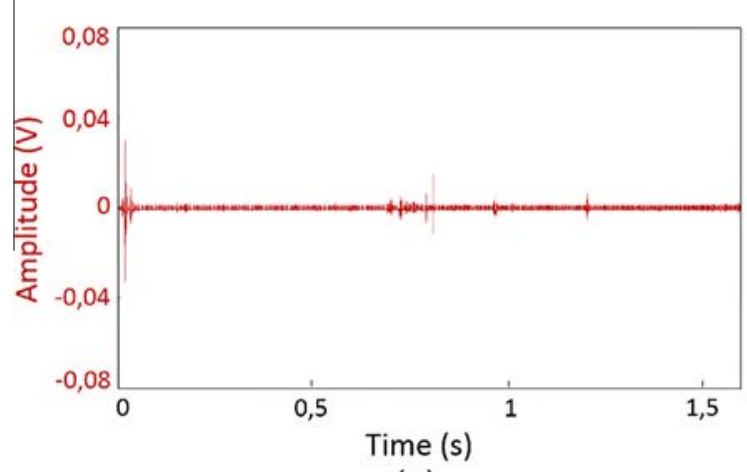

(a)

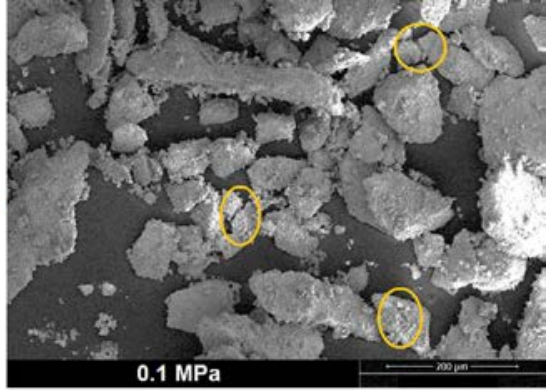

(b)

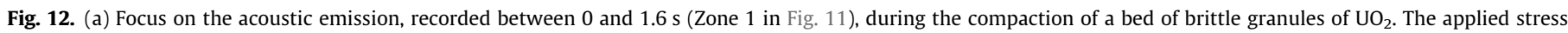
ranges from 0 to $0.1 \mathrm{MPa}$. (b) SEM observations of $\mathrm{UO}_{2}$ granules compacted at $0.1 \mathrm{MPa}$, emphasizing granule fragmentation.

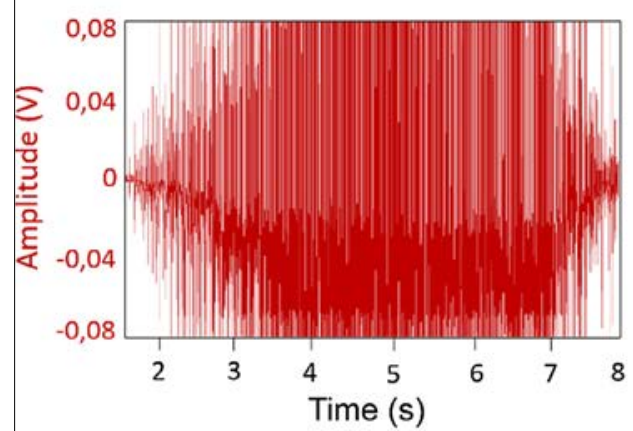

(a)

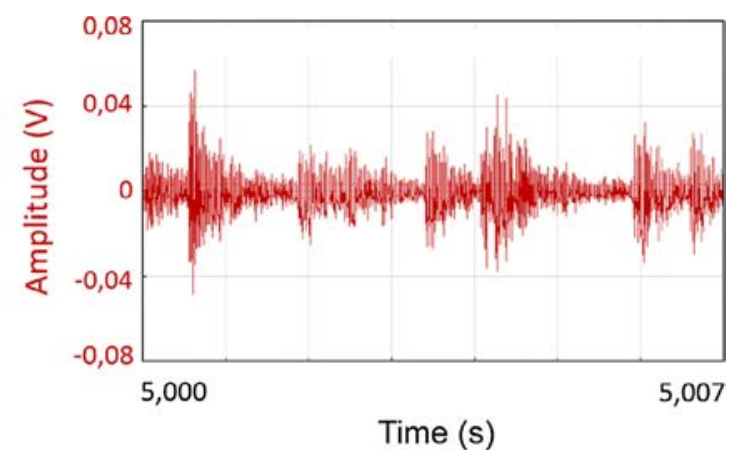

(b)

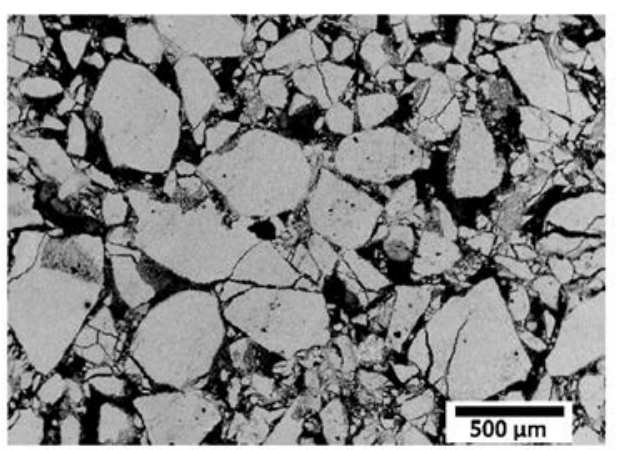

(c)

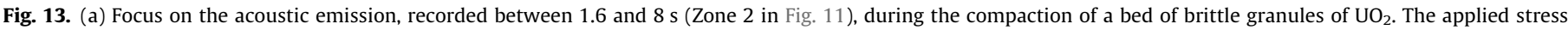
ranges from 0.1 to $180 \mathrm{MPa}$. (b) Focus on the burst signals recorded in the vicinity of time $t=5 \mathrm{~s}$. (c) $\mathrm{SEM}_{\text {observations of } \mathrm{UO}}$ granules compacted at $5 \mathrm{MPa}$

rearrangement becomes more and more difficult, which leads to a decrease in the rate of granule fragmentation.

The third zone, labelled 3 in Fig. 11, lies above $8 \mathrm{~s}$ in the time domain. It corresponds to an applied stress ranging from 180 to $600 \mathrm{MPa}$. The acoustic activity decreases drastically (Fig. 14a). At such applied stresses the granular medium seems to be frozen. The voids are very rare, which prevents the granule rearrangement (Fig. 14c). Some fragmentations of the granules still occur (Fig. 14a and b), but some granules are almost intact (Fig. 14c). The end of the noteworthy fragmentation process, that is the end of the significant process to increase the compactness of the material, can be really determined at the beginning of this third zone. It should be noted that the limit value of the applied stress related to the beginning of the third zone (here, $300 \mathrm{MPa}$ ) depends mainly on the granule cohesion, as shown subsequently.

Various AE signals are collected during the compaction of a bed of granules, and clustering them into classes with similar acoustic signatures seems useful prior to link them to a specific compaction mechanism. In many studies reported in literature (e.g. [15]), frequency characteristics have been proved to possess high characterization capacity. Nevertheless, for the problem of interest here, the material, composed of brittle particles, changes a lot during the compaction process, being a loose granular medium at the beginning of the test and a consolidated material at the end. In such conditions, the wave propagation is strongly affected by these changes, and frequency characteristics as well. As a consequence, typical frequency characteristics cannot be related to a specific mechanism in a straightforward manner. Supervised and unsupervised classification algorithms are widely used for finding a relationship between acoustic signatures and damage mechanisms of composite materials [29,30], such as delamination, fiber/matrix debonding, fiber breakage and matrix cracking. In our study we applied an unsupervised classification algorithm (namely, the kmeans algorithm [31]) by means of ten burst parameters including 


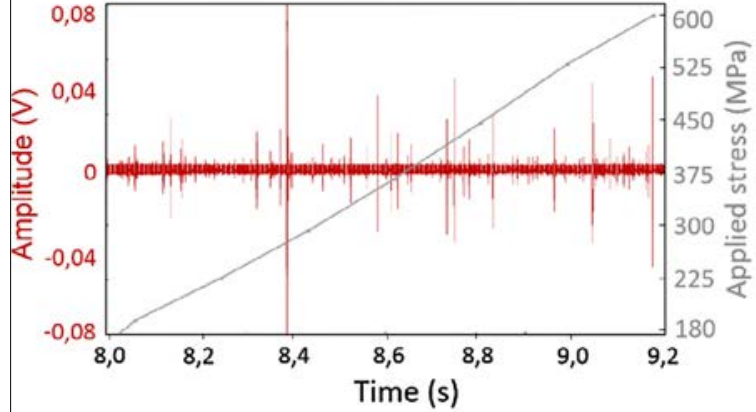

(a)

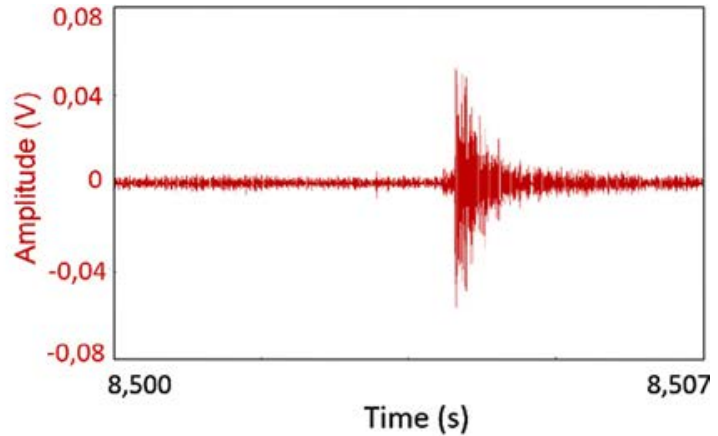

(b)

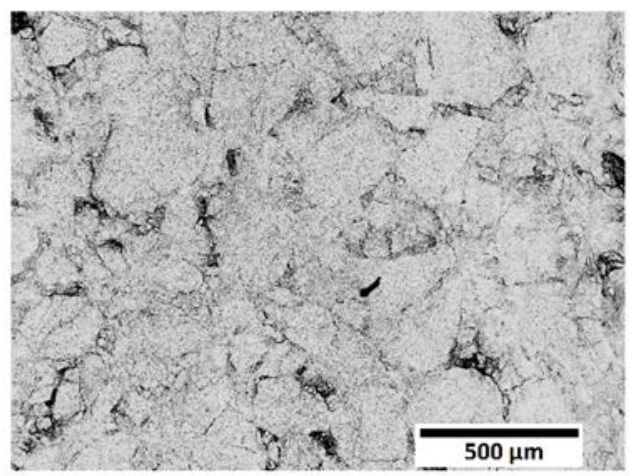

(c)

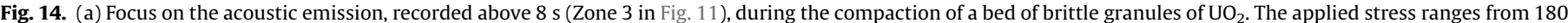
to $600 \mathrm{MPa}$. (b) Focus on the burst signals recorded in the vicinity of time $t=8.5 \mathrm{~s}$. (c) SEM observations of $\mathrm{UO}_{2}$ granules compacted at $300 \mathrm{MPa}$

rise time, amplitude, and energy. The optimal number of clusters was determined by using two statistical criteria (calculated in Noesis $^{\circledR}$ software), namely the standard deviation of the AE parameters in one cluster and the standard deviation of the signal between two clusters. The principal component analysis (included in Noesis ${ }^{\circledR}$ software) led to four classes but it appeared impossible to link each class to a specific compaction mechanism unambiguously. It is probably due to the fact that the characteristics of the acoustic signals (e.g. amplitude, frequency, energy, etc.) associated to a specific mechanism change a lot during the compaction test. A deeper study has to be performed to better constrain the problem.

\subsection{Impact of the granule size on the fragmentation}

The granule fragmentation is the sole mechanism that is well identified by a specific AE signal. Therefore, it is interesting to study the impact of the granule size on the fragmentation process through the $\mathrm{AE}$.

Four batches of granules of identical internal cohesion, but with different mean size and size spread, are considered, namely granules ranging between 45 and $160 \mu \mathrm{m}$, granules ranging between 160 and $500 \mu \mathrm{m}$, granules ranging between 800 and $1000 \mu \mathrm{m}$, and granules ranging between 0 and $1000 \mu \mathrm{m}$. The press chamber filled up with the granules was $12 \mathrm{~mm}$ in height. The beds of granules were compacted up to $600 \mathrm{MPa}$; the upper punch moved at the speed of $0.1 \mathrm{~mm} / \mathrm{s}$. In this experiment we considered discretized $\mathrm{AE}$ signals and the detection threshold of the acoustic events was fixed at $30 \mathrm{~dB}$. The choice for the discretization parameters (namely, the Peak Definition Time (PDT), the Hit Definition Time (HDT), and the Hit Lockout Time (HLT)) has been optimized for the tests with the $160-500 \mu \mathrm{m}$ granules: PDT $=200 \mu \mathrm{s}$, HDT $=800 \mu \mathrm{s}$, and $\mathrm{HLT}=1000 \mu \mathrm{s}$, the burst duration being between 1 and $5 \mathrm{~ms}$. Therefore, we comment hereafter only on the change in burst characteristics observed for the different granule batches, and not on their absolute values.

For each granule batch, the $\mathrm{AE}$ is characterized by the maximum amplitude of each burst signal depending on the density $\rho$ of the granule bed in Fig. 15. Even if the AE produced during compaction has an identical overall behavior, it is a function of the granule size. Indeed, as mentioned by several authors [8,23,5], large granule size increases the acoustic activity during compaction. The beginning of the $\mathrm{AE}$ does not depend on the mean size of the granules. Nevertheless, the more widespread the granule size distribution, the more gradually the burst amplitude increases. Regarding the $800-1000 \mu \mathrm{m}$ granules that have a very narrow size distribution, some burst amplitudes observed at the beginning of the acoustic activity are almost equal to the maximum amplitude observed during the test. On the contrary, the $0-1000 \mu \mathrm{m}$ granules that have the most widespread size distribution are those for which the bursts reach their maximum amplitude the most gradually. Fragmentation therefore does not take place in the same way according to the granule size distribution.

Since it is not dependent on the discretization parameters, the overall envelope of the maximum burst amplitudes (Fig. 15d) is a robust parameter to monitor fragmentation. The greater the mean diameter of the granules, the higher the maximum amplitude of the overall envelope of the maximum burst amplitudes (Fig. 16). This observation was also made by Waring and his co-authors [8] for $\mathrm{NaCl}$ particles of a few hundreds of micrometers. Regarding the $45-160 \mu \mathrm{m}$ granules, half of the bursts have an amplitude lower than or equal to $33 \mathrm{~dB}$; the low amplitudes may be thus associated to rearrangement and fragmentation of granules whose size is less than $160 \mu \mathrm{m}$. Note that this low-amplitude bursts may be "masked" by bursts of higher amplitude. The end of the AE depends on the mean size of the granules (Fig. 17), as it has been noted by Rouèche and her co-authors [32] for the compaction of sand of a few hundreds of micrometers. The mean stress and the 


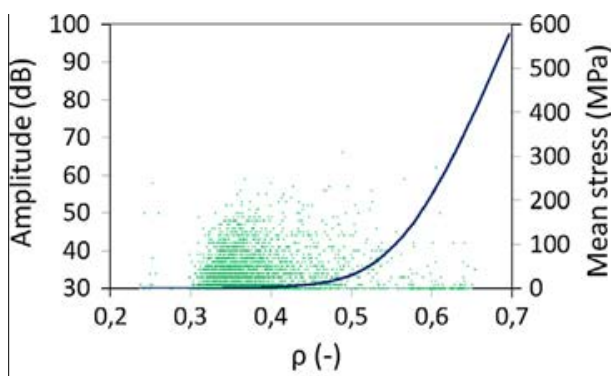

(a)

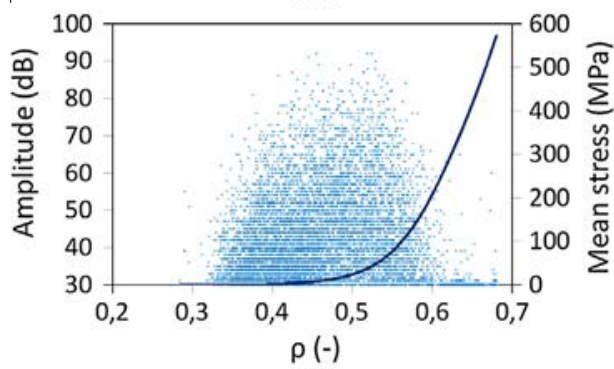

(c)

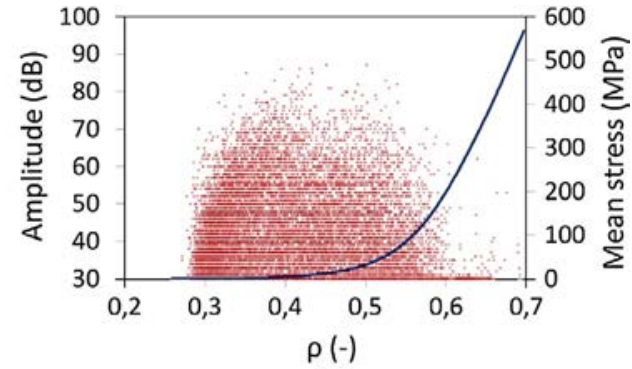

(b)

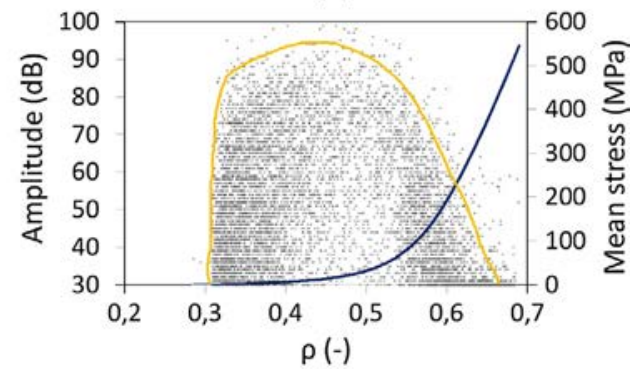

(d)

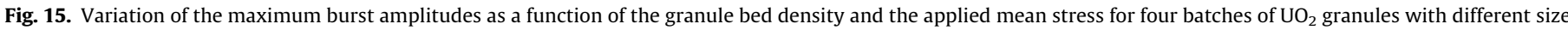

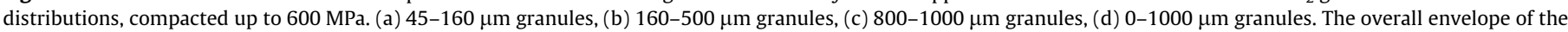

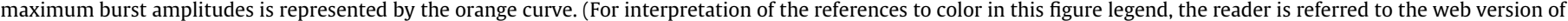
this article.)

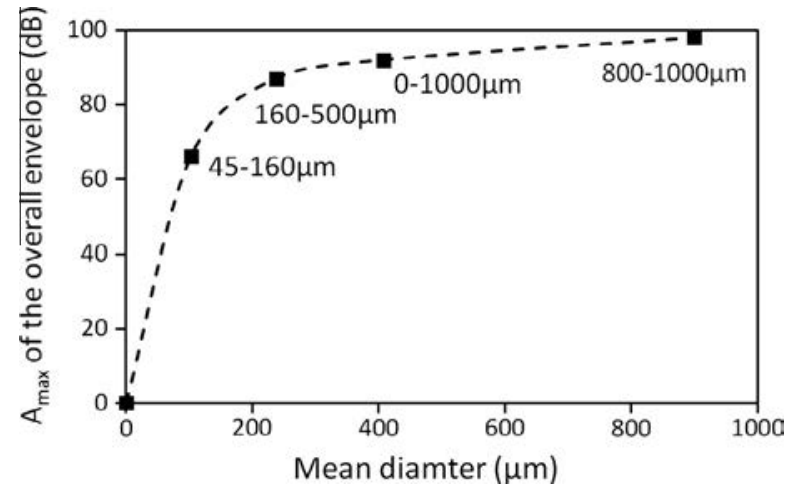

Fig. 16. Variation of the maximum amplitude of the overall envelope of the maximum burst amplitudes as a function of the mean diameter of the granule batches.

medium density from which the AE stops increase with the mean size of the initial granules.

\subsection{Impact of the granule cohesion on the fragmentation}

The granules have a natural cohesion due to imbrication of particles, Van der Waals attractions, and electrostatic forces. This cohesion can be increased considerably by creating strong bonds between the particles using heat treatment (from about $800{ }^{\circ} \mathrm{C}$ ), without significant changes in the particle size and structure. It is interesting to study the impact of the granule cohesion on the fragmentation process through the AE.

Four batches of granules of identical mean size and size spread are considered, namely granules ranging between 160 and $500 \mu \mathrm{m}$, but thermally consolidated at $600^{\circ} \mathrm{C}, 800{ }^{\circ} \mathrm{C}, 1000^{\circ} \mathrm{C}$, and $1100^{\circ} \mathrm{C}$, respectively. As previously, the press chamber filled up with the granules was $12 \mathrm{~mm}$ in height; the beds of granules were compacted up to $600 \mathrm{MPa}$; the upper punch moved at the speed of $0.1 \mathrm{~mm} / \mathrm{s}$.

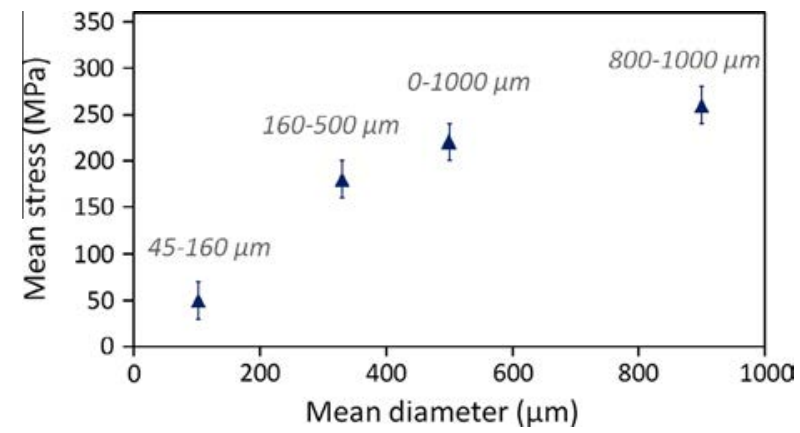

Fig. 17. Variation of the mean stress corresponding to the end of the recorded $\mathrm{AE}$ as a function of the mean diameter of the granule batches.

First, we observed that the bursts generated by the fragmentation of the thermally-consolidated granules have a waveform similar to that of the unconsolidated granules, namely a fast rise time and a slow decay of amplitude. As the breaking strength is greater for the consolidated granules than for the unconsolidated ones, the amplitude of the acoustic signals generated by the fragmentation of the consolidated granules is expected to be higher, and therefore, the probability of detecting the AE signals should be higher. Nevertheless, the waves may be attenuated during their propagation in the granular medium and the experimental structure, from the source mechanism to the $\mathrm{AE}$ sensor.

We then considered discretized AE signals and the detection threshold of the acoustic events was fixed at $30 \mathrm{~dB}$. The discretization parameters of the AE events are identical to those described in Section 4.2. For each granule batch, the $\mathrm{AE}$ is characterized by the maximum burst amplitude depending on the density $\rho$ of the granule bed (Fig. 18). For comparison, the amplitudes of the AE signals for the unconsolidated $160-500 \mu \mathrm{m}$ granules are also shown in Fig. 18. It is important to note that the first bursts are recorded, although the applied mean stress is less than $1 \mathrm{MPa}$. At the very beginning of the compaction test, the burst amplitudes increase 


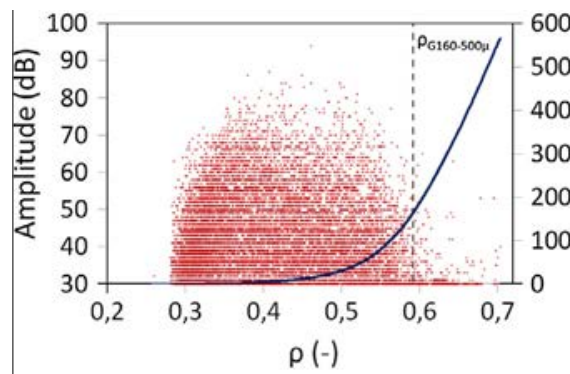

(a)

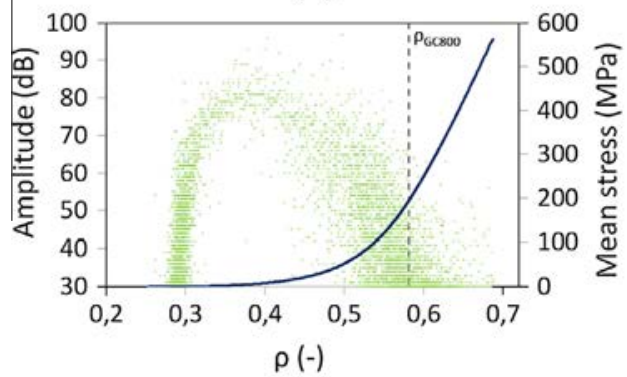

(c)

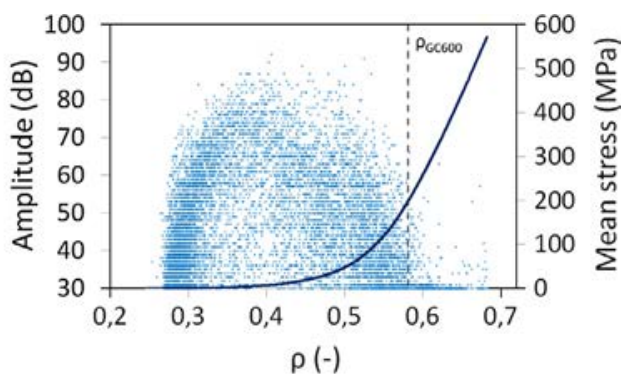

(b)

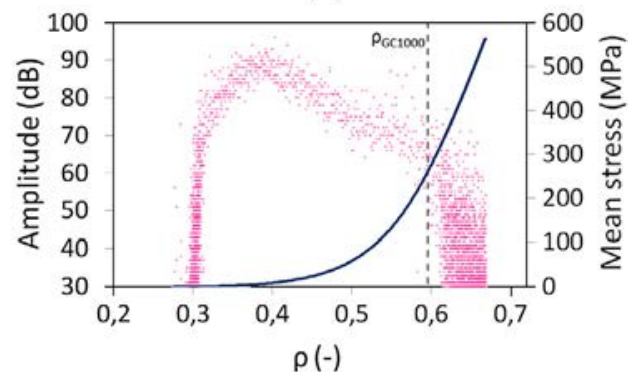

(d)

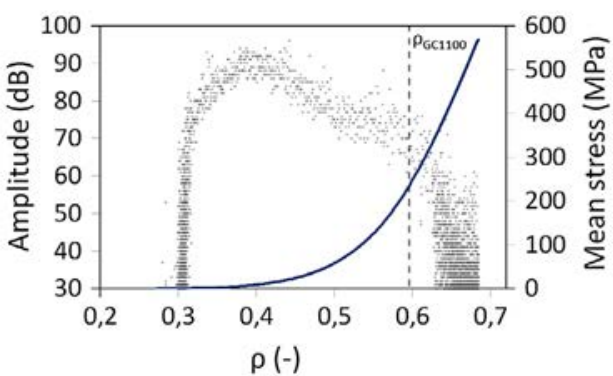

(e)

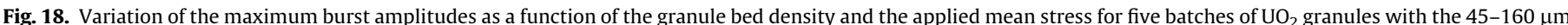

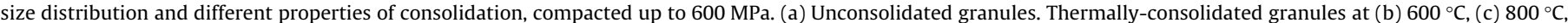
(d) $1000^{\circ} \mathrm{C}$, and (e) $1100^{\circ} \mathrm{C}$.

more and more abruptly with increasing consolidation of the granules. In particular, for the granules that were consolidated at temperatures above $800{ }^{\circ} \mathrm{C}$, the burst amplitude distribution is narrow, and some burst amplitudes are almost equal to the maximum amplitudes observed during the test. The narrow distribution of the maximum burst amplitudes is still observed for greater density $\rho$ of the granule bed (and higher applied mean stress). For instance, the maximum burst amplitudes, recorded during the compaction of the $1100^{\circ} \mathrm{C}$-consolidated granules, range from 82 to $94 \mathrm{~dB}$ for $\rho$ varying from 0.35 to 0.4 . In fact, this observed narrow distribution is mainly due to the strong increase in the amplitude of the raw signal and the very rapid succession of the discrete acoustic emissions. Indeed, the detection threshold (set at $30 \mathrm{~dB}$ ) and the discretization parameters, selected for the $160-500 \mu \mathrm{m}$ granules, do not allow to reveal bursts of lower amplitude. In other words, failure to observe low amplitude bursts may originate from the discretization conditions of the raw signal that may not be optimal for studying AE produced by the consolidated granules.

We can also note that the maximum amplitude of the overall envelope of the maximum burst amplitudes increases with increasing temperature for granule consolidation (Fig. 18), and therefore with increasing breaking stress (Fig. 19). For the unconsolidated granules the majority of the maximum burst amplitudes is lower than $75 \mathrm{~dB}$, whereas for the $1100{ }^{\circ} \mathrm{C}$-consolidated granules it is lower than $95 \mathrm{~dB}$ (Fig. 18). When the density of the granule bed is close to that of the granules, the burst amplitudes are con-

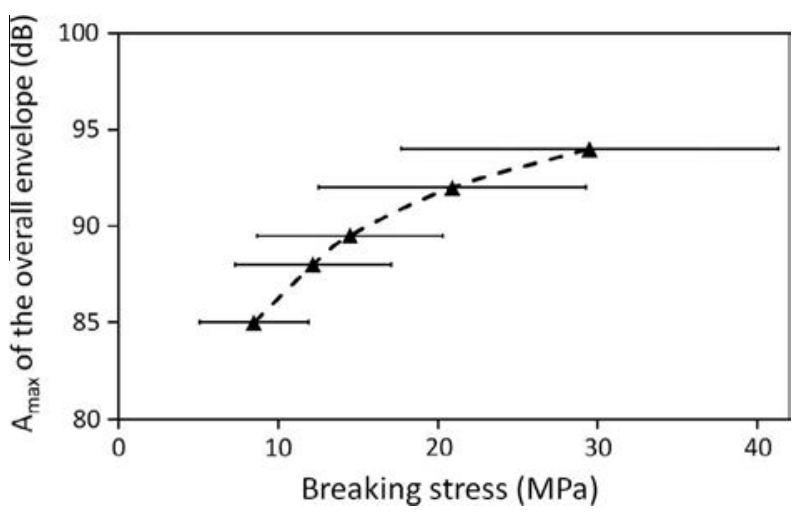

Fig. 19. Variation of the maximum amplitude of the overall envelope of the maximum burst amplitudes as a function of the breaking stress of the granules.

siderably reduced and the waveform characteristic of the fragmentation is no longer observed. We assume that the majority of the granules is fragmented. We can then define a mean stress corresponding to the end of the recorded $\mathrm{AE}$ for each batch of granules. Nevertheless, it is likely that the AE recorded at the end of the compaction test for the $1000{ }^{\circ} \mathrm{C}$ - and $1100{ }^{\circ} \mathrm{C}$-consolidated granules also corresponds partly to fragmentation. In addition, the mean stress corresponding to the end of the recorded $\mathrm{AE}$ increases 


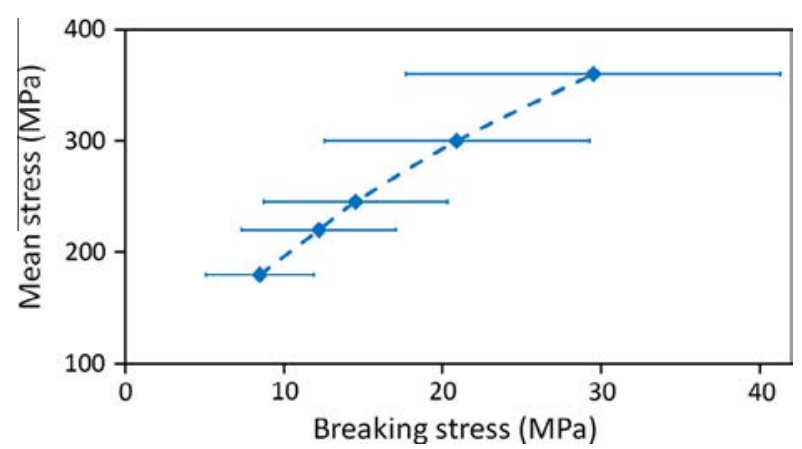

Fig. 20. Variation of the mean stress corresponding to the end of the recorded $\mathrm{AE}$ as a function of the breaking stress of the granules.

almost linearly with the breaking stress of granules (Fig. 20). This result demonstrates the advantage of following the compaction of fragile particles by AE. We observed that, beyond the mean stress corresponding to the end of the significant fragmentation identified by $\mathrm{AE}$, the granular media continue to densify, whatever the cohesion of their particles. This means that fragmentation must continue to contribute to the densification of the compact, but secondarily.

\section{Conclusion}

The goal of this study was to identify in situ the mechanisms that occur during the compaction of brittle Uranium Dioxide $\left(\mathrm{UO}_{2}\right)$ particles of a few hundred micrometers, and more specifically the particle fragmentation that is linked to the open porosity of the nuclear matter. Since the rupture of particles (even unconsolidated) generates acoustic signals that can be detected by piezoelectric sensors, the Acoustic Emission (AE) technique has been used to control the microstructure of the compact. The acoustic signature of the fragmentation of a single $\mathrm{UO}_{2}$ particle has been well identified. The waveform is defined by a short rise time and an exponential-like decay of the signal envelope. The AE activity during the compaction of a bed of $\mathrm{UO}_{2}$ particles is significant. The major difficulty is to identify uniquely the different mechanisms through the numerous acoustic signals whose characteristics vary as the wave propagation strongly evolves during the compaction process. Spectral analysis of the signals, as well as unsupervised classification algorithm together with principal component analysis, have been inefficient. A deeper study has to be performed to better constrain the problem. More specifically, processing of acoustic signals must be flexible enough to adapt to the strong variations in the signal characteristics and to allow for a more quantitative data exploitation.

Therefore, the waveform is the most reliable descriptor of the fragmentation process. Three zones of acoustic activity, strongly related to the applied stress, have been clearly defined from analysis of the continuous signals recorded during the compaction process of a bed of $\mathrm{UO}_{2}$ particles. They correspond mainly to particle rearrangement and/or fragmentation. The end of the noteworthy fragmentation process has been clearly defined as the end of the significant process that increases the compactness of the material. The impact of the particle size and cohesion on the AE activity, and then on the fragmentation domain, has been analyzed through the discrete AE signals. The greater the mean diameter of the particles, the higher the maximum amplitude of the burst signals, and the greater the mean stress corresponding to the end of the recorded $\mathrm{AE}$. Moreover, the maximum burst amplitude increases with increasing particle cohesion. Some of these results are supported by results of numerical simulations found in the literature. Numer- ical simulation can be a useful tool for a description of the evolution of the microstructure of a granular medium under compaction, and then for the quantification of the fragmentation. The AE technique is a simple and effective way to control the compaction of fragile particles.

\section{References}

[1] D.-H. Nguyen, E. Azéma, Ph. Sornay, F. Radjai, Bonded-cell model for particle fracture, Phys. Rev. E 91 (2015) 022203.

[2] D.-H. Nguyen, E. Azéma, F. Radjai, Ph. Sornay, Effect of size polydispersity versus particle shape in dense granular media, Phys. Rev. E 90 (2014) 012202

[3] D.-H. Nguyen, E. Azéma, Ph. Sornay, F. Radjai, Effects of shape and size polydispersity on strength properties of granular materials, Phys. Rev. E 91 (2015) 032203.

[4] E. Rémy, S. Picart, S. Grandjean, T. Delahaye, N. Herlet, P. Allegri, O. Dugne, R. Podor, N. Clavier, P. Blanchart, A. Ayral, Calcined Resin Microsphere Pelletization (CRMP): a novel process for sintered metallic oxide pellets, J. Eur. Ceram. Soc. 32 (2012) 3199-3209.

[5] B. Chen, J. Liu, Investigation of effects of aggregate size on the fracture behavior of high performance concrete by acoustic emission, Constr. Build. Mater. 21 (8) (2007) 1696-1701.

[6] K. Ohno, M. Ohtsu, Crack classification in concrete based on acoustic emission, Constr. Build. Mater. 24 (12) (2010) 1339-2346.

[7] S. Rouchier, M. Woloszyn, G. Foray, J.-J. Roux, Characterization of concrete and mortar racking by digital image correlation and acoustic emission, Eur. J Environ. Civil Eng. 17 (6) (2013) 467-477.

[8] M.J. Waring, M.H. Rubinstein, J.R. Howard, Acoustic emission of pharmaceutical materials during compression, Int. J. Pharm. 36 (1) (1987) 29-36.

[9] P. Baud, E. Klein, T.-F. Wong, Compaction localization in porous sandstones: spatial evolution of damage and acoustic emission activity, J. Struct. Geol. 26 (4) (2004) 603-624.

[10] P.A. Johnson, B. Ferdowsi, B.M. Kaproth, M. Scuderi, M. Griffa, J. Carmeliet, R.A. Guyer, P.-Y. Le Bas, D.T. Trugman, C. Marone, Acoustic emission and microslip precursors to stick-slip failure in sheared granular material, Geophys. Res. Lett. 40 (21) (2013) 5627-5631.

[11] M. Janecek, R. Krala, P. Dobroma, F. Chmelika, V. Supikb, F. Holländerb, Mechanisms of plastic deformation in AZ31 magnesium alloy investigated by acoustic emission and transmission electron microscopy, Mater. Sci. Eng. A $462(1-2)$ (2006) 311-315.

[12] C. Santulli, I.M. De Rosa, F. Sarasini, Acoustic emission for monitoring the mechanical behaviour of natural fibre composites: a literature review, Compos. Part A: Appl. Sci. Manuf. 40 (9) (2009) 1456-1469.

[13] S. Momon, M. Moevus, N. Godin, M. R'Mili, P. Reynaud, G. Fantozzi, G. Fayolle Acoustic emission and lifetime prediction during static fatigue tests on ceramic-matrix-composite at high temperature under air, Compos. Part A: Appl. Sci. Manuf. 41 (7) (2010) 913-918.

[14] S.A. Papargyri-Mpeni, D.A. Papargyris, X. Spiliotis, A.D. Papargyris, Comparison of acoustic emission produced during bending of various ceramic and short fiber oxide ceramic matrix composites, J. Acoust. Emission 28 (2010) 246-275.

[15] K.G. Dassios, D.G. Aggelis, E.Z. Kordatos, T.E. Matikas, Cyclic loading of a SiCfiber reinforced ceramic matrix composite reveals damage mechanisms and thermal residual stress state, Compos. Part A: Appl. Sci. Manuf. 44 (2013) 105 113.

[16] S. Masmoudi, A. El Mahi, S. Turki, R. El Guerjouma, Mechanical behaviour and health monitoring by acoustic emission of unidirectional and cross-ply laminates integrated by piezoelectric implant, Appl. Acoust. 86 (2014) 118125.

[17] O.Y. Andreykiv, M.V. Lysak, O.M. Serhiyenko, V.R. Skalsky, Analysis of acoustic emission caused by internal cracks, Eng. Fract. Mech. 68 (11) (2001) 1317 1333.

[18] S. Bouras, I. Zerizer, F. Gheldane, M.T. Bouazza, B. Bouzabata, Study of the resistance to crack propagation in alumina by acoustic emission, Ceram. Int. 34 (8) (2008) 1857-1865.

[19] P. Antonaci, P. Bocca, D. Masera, Fatigue crack propagation monitoring by acoustic emission signal analysis, Eng. Fract. Mech. 81 (2012) 26-32.

[20] N. Parida, B.B. Pani, B.R. Kumar, Acoustic emission assisted compaction studies on iron, iron-aluminium and iron-cast iron powders, Scripta Mater. 37 (11) (1997) 1659-1663.

[21] T. Kathrina, R.D. Rawlings, Acoustic studies of the effect of SiC particle reinforcement on the compaction of alumina powder, J. Eur. Ceram. Soc. 17 (9) (1997) 1157-1166.

[22] J. Salonen, K. Salmi, A. Hakanen, E. Laine, K. Linsaari, Monitoring the acoustic activity of a pharmaceutical powder during roller compaction, Int. J. Pharm. 153 (1997) 257-261.

[23] E. Serris, L. Perier-Camby, G. Thomas, M. Desfontaines, G. Fantozzi, Acoustic emission of pharmaceutical powders during compaction, Powder Technol. 128 (2-3) (2002) 296-299.

[24] P. Reynaud, J. Dubois, D. Rouby, G. Fantozzi, E. Weynant, Acoustic emission monitoring of uniaxial pressing of ceramic powders, Ceram. Int. 18 (1992) 391-397. 
[25] Y.H.J. Au, S. Eissa, B.E. Jones, Receiver operating characteristic analysis for the selection of threshold values for detection of capping in powder compression, Ultrasonics 42 (1-9) (2004) 149-153.

[26] G. Kerboul, Etude de l'endommagement des produits céramiques crus par émission acoustique, PhD thesis INSA Lyon France, 1992.

[27] L. Hégron, Ph. Sornay, N. Favretto-Cristini, Compaction of a bed of fragmentable $\mathrm{UO}_{2}$ particles and associated acoustic emission, IEEE Trans. Nucl. Sci. 61 (4) (2014) 2175-2181.

[28] F. Fernandes, A.I. Syahrial, J.R. Valdes, Monitoring the œdometric compression of sands with acoustic emissions, Geotech. Test. J. 33 (5) (2010) 410-415.
[29] Y.A. Dzenis, J. Qian, Analysis of microdamage evolution histories in composite, Int. J. Solids Struct. 38 (2001) 1831-1854

[30] N. Godin, S. Huguet, R. Gaertner, L. Salmon, Clustering of emission acoustic signals collected during tensile tests on unidirectional glass/polyester composite using supervised and unsupervised classifiers, NDTE Int.: Indep. Non Destruct. Test. Eval. 37 (4) (2004) 253-265.

[31] A. Likas, N. Vlassis, J. Verbeek, The global k-means clustering algorithm, Pattern Recogn. 36 (2) (2003) 451-461.

[32] E. Rouèche, G. Thomas, L. Perier-Camby, E. Serris, Fragmentation de grains de sable. Suivi par émission acoustique et bilans de population, in: Proceedings De la Poudre au Matériau Massif, 2003. 